\title{
Energy-Environment Resolution
}

WHEREAS the countries of the world are striving to improve their living standards, and thus-in addition to adopting all appropriate conservatioin measures-must increase their energy consumptions in the long run,

WHEREAS the main energy sources at present are fossil fuels,

WHEREAS fossil fuels are finite in amount and will eventually be depleted, with the downturn in production expected to start early in the next century, if not before,

WHEREAS it is prudent to plan and begin conversion to the next energy-system by making use of the remaining fossil-fuel sources (and also other conventional energy sources, such as nuclear, etc.) to achieve a smooth changeover, which is expected to take half-a-century or so,

WHEREAS it is also prudent to preserve the diminishing stocks of the fossil fuels for non-fuel applications (such as lubricants, synthetic fibers, plastics, and fertilizers), for which there may be no substitutes,

WHEREAS the combustion products of fossil fuels are causing growing damage to our Biosphere (the only domain in the Universe that is known to be supportive of life) and especially to its living components through pollution, acidic precipitation, $\mathrm{CO}_{2}$, and carcinogens,

WHEREAS the combustion products and their harmful effects do not stop at the national boundaries,

WHEREAS it is of the utmost importance to keep The Biosphere clean and fit for life, and hence the energy sources and energy carriers as clean as possible,

WHEREAS there exist 'clean' primary energy sources,

WHEREAS there is a need for two types of energy carriers, namely, electricity (meeting about one-quarter of the demand at the consumer end) and fuel (meeting about threequarters of the demand),

WHEREAS there exists technology for the production and utilization of the environmentally most compatible and most efficient fuel-energy carrier, namely hydrogen,

WHEREAS there is a necessity for a self-regulating system, to ensure that Man-induced factors (energy or otherwise) do not harm The Biosphere or threaten life,
IT IS HEREBy ReSOLVED:

THAT products (energy carriers and otherwise) be made responsible for the harm they cause to The Biosphere and to life, directly or through their waste or their manufacture,

THAT the price of each product include an 'environmental surcharge' to cover its environmental damage,

THAT the environmental surcharge be used by appropriate authorities to undo such damage to The Biosphere, life, and Made-made structures; to cover related medical, restoration, and relief, expenses; and to compensate the victims,

THAT there must be international cooperation to ensure equitable and uniform application of the environmental surcharge.

ImPlementation of the Above Will Result in the following lasting and universal benefits:

ENSURE that eventually the present fossil-fuel system would be replaced by a clean and environmentally compatible energy system, the hydrogen energy system,

ENSURE that energy (fossil, nuclear, etc.) would be available for the change-over, thus resulting in a smooth change with no upheavals,

ENSURE that some supplies of fossil fuels would be preserved for non-fuel applications, for which there might be no substitutes,

PROMOTE world-wide economic development and hence international harmony as progressively less unproductive work would be required to undo the environmental damage; and, through the utilization of an efficient and renewable energy carrier,

SAVE The Biosphere and life from conceivable extinction by ensuring that products, their wastes, and manufacturing methods, would be environmentally compatible.

[Communicated by]
T. NEJAT VEZIROGLU, Director
Clean Energy Research Institute
University of Miami
Coral Gables
Florida 33134, USA.

[Communicated by] T. Nejat Veziroglu, Director University of Miami Florida 33134, USA.

\section{European Protected Areas Diploma's Twentieth Anniversary}

The European Diploma, now 20 years old, can be awarded at a government's request to natural areas, sites, or features, which are of international value and particularly of European interest from the point of view of protection of the natural heritage-by virtue of their scientific, cultural, aesthetic, and/or recreational, quality, and which are protected. The European Diploma places the site or feature under the sponsorship of the Council of Europe.

The first three diplomas were awarded in 1966 to the Nature reserves of Hautes-Fagnes in Belgium and of $\mathrm{Ca}-$ margue in France, and to the Peak District National Park in the United Kingdom. The Diploma is awarded for a period of five years, following an on-the-spot appraisal. It may be renewed after appraisal every five years, provided that the situation in the area is the same as when the award was made, and there has been no deterioration. An annual report on the situation of, and improvements to, the area has to be submitted to the Council of Europe. If a site is seriously endangered, the Diploma may be withdrawn.

The Committee of Experts on Protected Areas recently met in Strasbourg to consider the annual reports on the 21 areas currently holding the Diploma. It proposed that the Diploma be awarded to the Bayerischer Wald National Park (Federal Republic of Germany), in Category A, pro- vided certain conditions are met-including a gradual reduction in logging of the order of $50 \%$ and a proportionate increase in the size of the reserves.

Areas holding the Diploma are under constantly increasing pressures which endanger their priority objectives of ecosystem conservation. The renewal of the Diplomas awarded to seven Nature reserves and national parks was accompanied by certain recommendations and conditions as follows:

The Hautes-Fagnes Nature Reserve (Belgium) should draw up a management plan based on an analysis of ecological assets and maintain the typical appearance of its various types of vegetation. In the case of the Camargue Nature Reserve (France), the operational budget should be sufficient to ensure proper management. Oil prospecting and other development schemes in areas close to the Reserve should be discontinued if they constitute a risk for the Reserve's future existence.

In the Vanoise National Park (France) the building of the proposed Clou dam should be prohibited, as should the construction of ski lifts - particularly the one planned to link the resorts of Val d'Isère and Bonneval-sur-Arc. Improvements in Bonneval's economic situation should be sought only in solutions which do not jeopardize the sur- 
vival of the Park, which is of European interest. In the Western Pyrenees National Park (France), and peripheral areas, it is of the utmost importance that no further tourist facilities be built. Any exchange scheme allowing encroachments on the Park's territory in return for compensation in the peripheral zone is to be avoided.

In the Siebengebirge Nature Reserve (Federal Republic of Germany), the introduction of forest populations similar to those occurring naturally should be stipulated when management plans are revised. In the Kuscenneti National Park (Turkey), steps must be taken to ensure that the building of the Kocaçay dam does not affect the ecosystems of the lake and site, and to maintain the natural hydrological system of Lake Manyas with natural seasonal variations in water-levels. Lastly, in the Peak District National Park (United Kingdom), the legal vacuum which currently allows quarries to be reopened must be filled as quickly as possible. The plan to build a reservoir at Longdendale should be abandoned once and for all.

Hayo H. Hoefstra \& Françoise Tondre Naturopa Newsletter-Nature

European Centre for Nature Conservation BP 431 R6

67006 Strasbourg Cedex, France.

\section{British Hedgehog Preservation Society}

Spearheaded by the Nature Conservancy Council, everincreasing numbers of British people are becoming conscious of our natural heritage and of the importance of conserving all aspects of it, be they animal, vegetable, or mineral. There are hundreds of organizations whose members aim at conservatioin in one form or another, and one of these, although its impact has been national, is unique in that it originated in Shropshire. The British Hedgehog Preservatioin Society is based in the village of Knowbury, five miles $(8 \mathrm{~km})$ to the east of Ludlow, just off the A4117 road as it climbs up to the heights of Clee Hill.

The Society was founded in April 1982 by Major Adrian Coles, of Knowbury House, and followed his discovery of a Hedgehog (Erinaceus europaeus) that was unable to escape from the pit, beneath a cattle-grid, into which it had accidentally fallen. Such an incident highlighted the problem that when a Hedgehog (or other small mammal or bird) falls into a cattle- or sheep-grid, the near-vertical walls of the pit beneath the grid are too steep for the animal to climb out, and the result is death by dehydration or starvation. The solution is to provide a means of escape by installing, in a corner of the grid-pit, a ramp or slope up which the 'prisoner' can walk to freedom. This can be made of concrete, metal, or wood - with a rough surface to assist a firm foothold - and the cost is negligible.

Being a County Councillor, Major Coles was in a position to persuade Shropshire County Council Highways Department to install escape-ramps in grids within its authority, and, by publicizing this, to encourage other County Councils to follow suit. Press and other media reports aroused such interest that the Society was launched, with three declared aims of:

(1) Taking the necessary steps to secure the practical welfare of the Hedgehog by having escape-ramps installed in ALL cattle/sheep grids on public and private lands;

(2) Educating people-especially the younger generation - to appreciate and respect ALL our natural wildlife. particularly Hedgehogs; and

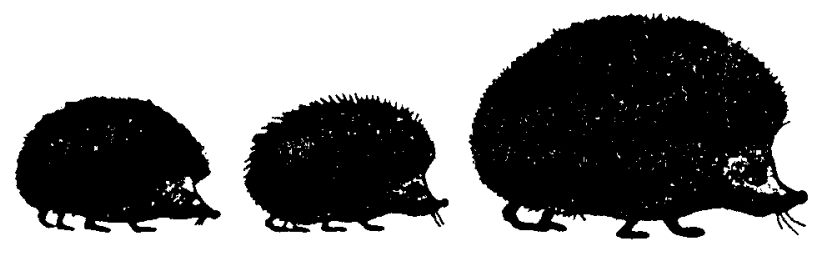

FIG. 1. Part of a family of Hedgehogs, of which the young usually number 4-8.

(3) Financing serious and much-needed research into the behavioural patterns of Hedgehogs.

Dr Patrick Morris, of the Department of Zoology, Royal Holloway College, London University, is an acknowledged expert on Hedgehogs, and is currently conducting investigations into the survival of that species in Britain. To date the Society has been able to provide $£ 4,000$ to help with this essential work, but much more money is needed. To help raise this and to cover ever-increasing costs, the Society has expanded its activities to include selling articles such as sweatshirts and tee shirts, ties, aprons, tea towels, ear studs, and other novelties, with a hedgehog motif-especially $\mathrm{Dr}$ Morris's own book, Hedgehogs.

The Society has a healthy and growing membership, and, as well as regularly circulating its own Newsletter, deals with many hundreds of queries from the public concerning the care of Hedgehogs, regularly releases material for the media, and collates information received concerning Hedgehog behaviour. Applications for membership should be addressed to the British Hedgehog Preservation Society at Knowbury House, Knowbury, Ludlow, Shropshire SY8 3JT, England (UK), enclosing a stamped self-addressed envelope.

\section{L.H.C. SHARP, Education Officer British Hedgehog Preservation Society Knowbury House Knowbury \\ Ludlow Shropsnire England, $U K$.}

\section{(Continued from page 268)}

It has been estimated that by the year 2000 , two-thirds of the world's total streamflow will be controlled by dams. At the world-scale, large dams are being completed at a rate of more than one per day ${ }^{\dagger}$ and river regulation schemes have destroyed very widely the integrity of the Catchment Ecobiomes and Ecosystems. Increasingly, long-distance water transfers from water-surplus catchments to water-deficient ones are becoming a serious alternative in water planning. The Ob Dam below the Irtysh confluence, for example, due for completion in AD 2010, is planned to divert impounded water south for $2,500 \mathrm{~km}$ in order to augment flows within the Amu-Darya River, and to provide irrigation supplies within Soviet central Asia and Kazakhstan. We may only guess at the consequences of such major engineering works on The Biosphere!

The WCB and the ISEE must direct themselves to safeguarding the World's natural rivers. Indeed, by directing attention to the progressive deterioration of the World's lotic ecosystems, we may convince this and future generations of the great urgency which exists for safeguarding our habitat, because it is only by managing our whole environment that we can hope to conserve our lotic ecosystems.

${ }^{\dagger}$ Petts, G.E. Impounded Rivers: Perspectives for Ecological Management. (Environmental Monographs \& Symposia, Gen. Ed. N. Polunin.) John Wiley \& Sons, Chichester-New York-Brisbane-Toronto-Singapore: xviii + 326, illustr., 1984.

GeofFrey E. PeTts, Lecturer Department of Geography University of Technology Loughborough

Leicestershire, England, $U K$. 